\title{
Valproic acid disables the Nrf2 anti-oxidant response in acute myeloid leukaemia cells enhancing reactive oxygen species-mediated killing
}

Yao Jiang ${ }^{1}$, Andrew D. Southam ${ }^{2}$, Sandro Trova ${ }^{2}$, Flavio Beke ${ }^{3}$, Bader Alhazmi ${ }^{1}$, Thomas Francis ${ }^{4}$, Anshul Radotra ${ }^{5}$, Alessandro di Maio ${ }^{2}$, Mark T. Drayson ${ }^{6}$, Chris M. Bunce ${ }^{2,7}$ and Farhat L. Khanim (iD) ${ }^{1,7 凶}$

(C) The Author(s) 2021

\begin{abstract}
BACKGROUND: We previously demonstrated the in vitro killing of AML cells by the combination of the lipid-lowering agent bezafibrate (BEZ) and the contraceptive hormone medroxyprogesterone acetate (MPA). A phase II trial demonstrated in vivo safety and efficacy of BEZ and MPA (BaP) in elderly, relapsed/refractory AML and high-risk myelodysplastic syndrome (MDS) patients. However, we observed dose-limiting toxicities in a second trial that attempted to improve outcomes via escalation of BaP doses. Thus we sought to identify a third repurposed drug that potentiates activity of low dose BaP (BaP $0.1 \mathrm{mM}$ ).

METHODS AND RESULTS: We demonstrate that addition of a commonly used anti-epileptic, valproic acid (VAL) to low dose BaP (BaP $0.1 \mathrm{mM})(\mathrm{VBaP})$ enhanced killing of $\mathrm{AML}$ cell lines/primary AML cells to levels similar to high dose BaP (BaP $0.5 \mathrm{mM})$. Similarly, addition of VAL to BaP $0.1 \mathrm{mM}$ enhanced reactive oxygen species (ROS), lipid peroxidation and inhibition of de novo fatty acid synthesis. Overexpression of Nrf2 in K562 and KG1a completely inhibited ROS production and rescued cells from VAL/BaP $0.1 \mathrm{mM} /$ VBaP killing.
\end{abstract}

CONCLUSIONS: Given the good safety data of low-dose BaP in elderly/relapsed/refractory AML patients, and that VAL alone is welltolerated, we propose VBaP as a novel therapeutic combination for AML.

British Journal of Cancer (2022) 126:275-286; https://doi.org/10.1038/s41416-021-01570-z

\section{INTRODUCTION}

Acute myeloid leukaemias (AML) are aggressive blood cancers that, if untreated, kill patients quickly by crippling production of normal blood cells. Treatment is focused on the high rate of cell division in AML cells but this focus also kills the rapidly dividing progenitors of normal blood cells. Consequently, treatment is tempered into short cycles that allow recovery of normal blood cell production from haemopoietic stem cells (HSCs) between treatment cycles. AML is most prevalent in the elderly and $>70 \%$ of patients are older than 60 years at diagnosis. Many patients, cannot tolerate these repeated cycles of intensive cytotoxic chemotherapy because of their age and disease related frailty $[1,2]$. Thus, there is an urgent need to identify therapies that target cancer cell characteristics with no/limited toxicity to normal cells and ideally a good known clinical safety profile.

Drug repurposing (redeployment), where existing drugs are used to treat conditions outside of their approved indications [3], is a proven approach to generate effective low toxicity therapies. This strategy has led to successful blood cancer treatments including all-trans retinoic acid (ATRA) and arsenic trioxide in acute promyelocytic leukaemia [4], and thalidomide in myeloma
[5]. We have demonstrated that $\mathrm{BaP}$, the redeployed combination of bezafibrate (BEZ) and medroxyprogesterone acetate (MPA), has in vitro and in vivo anticancer activity in $A M L$, chronic lymphocytic leukaemia (CLL) and non-Hodgkins lymphoma including endemic Burkitts lymphoma [6-11]. Our first clinical trial in AML reported the safety and efficacy of low dose BaP (400 mg per day BEZ and $400 \mathrm{mg}$ per day MPA) in 20 patients (19 AML, 1 high-risk myelodysplasia) for whom chemotherapy was not an option and predicted median survival was 7 weeks (ISRCTN50635541) [10]. Despite being administered continuously rather than in short cycles, no reaction was seen between the drugs and no patient exhibited haematological toxicity from BaP with $11 / 20$ patients taking BaP alone for $>4$ weeks. One patient reverted from high risk myelodysplastic syndrome (MDS) and remained transfusion independent for $>200$ weeks of therapy and $3 \mathrm{AML}$ patients gained major improvements in blood cell production for 22-30 weeks; in one, marrow was available to document a partial $\mathrm{AML}$ response. This trial used BEZ at lipid-lowering doses that were substantially lower than those that delivered maximal antiAML activity in vitro [11]. Similarly, MPA was delivered at just under half the optimum in vitro doses. In a subsequent trial in 16

\footnotetext{
${ }^{1}$ School of Biomedical Sciences, Institute of Clinical Sciences, University of Birmingham, Birmingham, UK. ${ }^{2}$ School of Biosciences, University of Birmingham, Birmingham, UK. ${ }^{3}$ CRUK Cancer Institute, University of Cambridge, Cambridge, UK. ${ }^{4}$ Centre for Human \& Applied Physiological Sciences, School of Basic \& Medical Biosciences, King's College London, London, UK. ${ }^{5}$ University Hospitals Coventry and Warwickshire, Clifford Bridge Rd, Coventry, UK. ${ }^{6}$ Institute of Immunology and Immunotherapy, University of Birmingham, Birmingham, UK. ${ }^{7}$ These authors contributed equally: Chris M. Bunce, Farhat L. Khanim. ${ }^{凶}$ email: F.L.Khanim@bham.ac.uk
}

Received: 7 June 2021 Revised: 27 August 2021 Accepted: 28 September 2021

Published online: 22 October 2021 
AML patients for whom chemotherapy was not an option (ISRCTN99131400), an increased dose of MPA at $1000 \mathrm{mg}$ per day was well tolerated. However, a twelve fold escalation of BEZ was not well tolerated mainly due to either a rise in Creatinine Kinase (CK) or low estimated glomerular filtration rate (eGFR), resulting in interruptions or changes in BEZ doses [12]. The observed BEZ related toxicity in this trial was due to the frail nature of the patients caused by their age, poor kidney function, disease and in some cases prior chemotherapy treatments. In marked contrast, $\mathrm{BaP}$, at the same high drug doses (adjusted per/ $\mathrm{kg}$ ), was well tolerated in a separate trial in paediatric Burkitts Lymphoma patients (ISRCTN34303497) [8].

Given the success of low dose BaP in our first clinical trial and the problems associated with delivering high dose BEZ in older frail AML patients, we sought to identify an adjunctive low toxicity drug that potentiated the activity of low dose BaP. A screen of our in-house drug repurposing library (FMC) identified the antiepileptic medication valproic acid (VAL) as a strong candidate. We demonstrate here that low dose $\mathrm{BaP}$, which uses $\mathrm{BEZ}$ at 0.1 $\mathrm{mM}$ (hereafter referred to as $\mathrm{BaP} 0.1 \mathrm{mM}$ ), when combined with VAL $(\mathrm{VBaP})$ recapitulates selective killing of primary $\mathrm{AML}$ blasts and $A M L$ cell lines to levels that are similar to high dose $\mathrm{BaP}(\mathrm{BaP}$ $0.5 \mathrm{mM}$ ), whilst not killing primary $\mathrm{CD} 34^{+\mathrm{ve}}$ haemopoietic stem/ progenitor cells (HSPCs) or healthy donor blood cells.

We also demonstrate that killing of AML cells by VBaP was associated with enhanced generation of reactive oxygen species (ROS) when compared to BaP $0.1 \mathrm{mM}$, although not to the levels of BaP $0.5 \mathrm{mM}$. We demonstrate that VAL treatment of AML cells inhibits the essential Nrf2 antioxidant response pathway by suppressing Nrf2 mRNA and protein expression and activity. Furthermore, induction of ROS and loss of viability by BaP and $\mathrm{VBaP}$ was rescued by overexpression of Nrf2. Thus, the triple repurposed drug combination of $\mathrm{VBaP}$ works by targeting the inherent sensitivity of $A M L$ cell to oxidative stress $[13,14]$ by inducing ROS whilst attenuating the anti-oxidant response.

\section{METHODS \\ Chemicals and reagent}

Valproic acid (VAL, $0.6 \mathrm{M}$ in $\mathrm{dH}_{2} \mathrm{O}$ ), bezafibrate (BEZ, $0.5 \mathrm{M}$ in DMSO), and medroxyprogesterone acetate (MPA, $5 \mathrm{mM}$ in ethanol) were purchased from Sigma-Aldrich (UK). The active metabolite of vitamin D3, 1,25 dihydroxy vitamin D3 (VD3) and all-trans retinoic acid (ATRA) were purchased from Cambridge Biosciences, and prepared as $1 \mathrm{mM}$ stocks in ethanol. All stocks were stored at $-20^{\circ} \mathrm{C}$.

\section{Cell culture and treatment}

KG1a, K562, HL60, NB4 cells were obtained from DSMZ and verified by regular STR profiling. Cell lines were maintained in RPMI 1640 media supplemented with $10 \%$ foetal bovine serum (FBS), $100 \mu \mathrm{g} / \mathrm{ml}$ penicillin and $100 \mathrm{U} / \mathrm{ml}$ streptomycin in a humidified incubator at $37^{\circ} \mathrm{C}$ with $5 \% \mathrm{CO}_{2}$. Primary blood samples from AML patients and normal donors were obtained as surplus to diagnosis samples and from normal donors (REC numbers 12/NW/0742 and ERN_17-0065). Healthy donor blood was obtained after informed consent under University of Birmingham (UoB) local ethical approval ERN_17-0065. Peripheral blood mononuclear cells (PBMCs) were purified by density centrifugation through Ficoll and plated at $1 \times 10^{6}$ cells $/ \mathrm{ml}$ in RPMI1640 media supplemented with $10 \%$ foetal bovine serum (FBS), $100 \mu \mathrm{g} / \mathrm{ml}$ penicillin and $100 \mathrm{U} / \mathrm{ml}$ streptomycin.

\section{Drug treatments}

Cells were treated with either solvent control (CON), $0.6 \mathrm{mM}$ Valproic acid (VAL), high dose BaP: $0.5 \mathrm{mM}$ BEZ and $5 \mu \mathrm{M}$ MPA (BaP $0.5 \mathrm{mM}$ ), Low dose BaP: $0.1 \mathrm{mM}$ BEZ and $5 \mu \mathrm{M}$ MPA (BaP $0.1 \mathrm{mM}$ ), or the combination of VAL $0.6 \mathrm{mM}$ and $\mathrm{BaP} 0.1 \mathrm{mM}$ (VBaP).

\section{Flow cytometry}

All flow cytometry was performed on a BD FACS Calibur utilising CellQuest Pro software and analysed using FlowJo Software.

\section{Cell viability}

Cell viability was determined using one of three assays as specified in the text. Cells were treated in $200 \mu$ in triplicate wells in 96-well plates at $1-2 \times 10^{4}$ cells/well for cell lines and $2 \times 10^{5}$ cells/well for primary cells. Viability was assessed using either: CellTiter-Blue ${ }^{\circledR}$ reagent according to the manufacturer's instructions (Promega, UK), viable cell counts using manual counts, or by flow cytometry utilising viable gates and fluorescent Cytocount beads (Biolegend, UK). Primary samples were harvested, stained with anti-CD34-APC and anti-CD117-PE (BD Biosciences, UK) before analysis by flow cytometry utilising viable gates and fluorescent Cytocount beads.

\section{Annexin V and cell cycle analysis}

Apoptosis was assessed using an Annexin V-FITC kit (BD Biosciences) according to the manufacturer's instructions. Cell cycle was analysed by resuspending cell pellets from $500 \mu \mathrm{l}$ cell suspensions in $500 \mu \mathrm{l}$ cell cycle buffer $(30 \mu \mathrm{g} / \mathrm{ml} \mathrm{Pl}, 0.1 \mathrm{mM}$ sodium chloride, $1 \%$ sodium citrate, $1 \%$ Triton $\mathrm{X} 100$ ) and incubating at $4{ }^{\circ} \mathrm{C}$ for $4 \mathrm{~h}$ before flow cytometry analysis.

\section{Assessment of reactive oxygen species and mitochondrial superoxide (mitosox)}

MitoSOX Red (ThermoFisher Scientific, UK) was used to assess mitochondrial superoxide (mitosox) levels. PBS-washed cells were resuspended in $200 \mu \mathrm{l} 37^{\circ} \mathrm{C}$ PBS containing $5 \mu \mathrm{M}$ MitoSOX Red, incubated at $37^{\circ} \mathrm{C}$ for $10 \mathrm{~min}$ and then analysed by flow cytometry. Reactive oxygen species (ROS) were measured using carboxy- $\mathrm{H}_{2}$ DCFDA (5-(and-6)-carboxy-2,7dichlorodihydrofluorescein diacetate, Invitrogen). Cells were treated with solvent control/drugs at $37^{\circ} \mathrm{C}$ and $10 \mu \mathrm{M}$ carboxy- $\mathrm{H}_{2} \mathrm{DCFDA}$ added to $0.5 \mathrm{ml}$ cell suspension for the final $45 \mathrm{~min}$ before washing with PBS and flow cytometry.

\section{GSH/GSSG assay}

Reduced glutathione (GSH) and oxidised glutathione (GSSG) were measured with GSH/GSSG-Glo ${ }^{\text {TM }}$ Assay Kit (Promega,UK) according to the manufacturer's instructions. Cells were treated for $4 \mathrm{~h}$ before $5 \times 10^{4}$ cells were transferred into 96-well luminescence plates and luminescence recorded using a luminometer (Victor X3, Perkin Elmer Inc., UK).

\section{Prostaglandin ELISAs}

Prostaglandin $\mathrm{D}_{2}$-MOX EIA kit (Cayman Chemicals, USA) was used to determine prostaglandin levels. After treating $5 \times 10^{6}$ cells in $5 \mathrm{ml}$ media for $4 \mathrm{~h}$, cells were harvested with $1 \mathrm{ml}$ culture media and homogenised using a Precellys 24 ceramic bead homogenisation system (Bertin instruments, UK). Prostaglandins were extracted using C18 reverse phase extraction columns (Chromabond, Fisher, UK) and levels determined by ELISA according to the manufacturer's instructions.

\section{Western blot}

$5 \times 10^{6}$ treated cells were lysed in RIPA buffer ( $1 \% \mathrm{v} / \mathrm{v}$ NP40, $0.5 \% \mathrm{w} / \mathrm{v}$ sodium deoxycholate, $0.1 \% \mathrm{w} / \mathrm{v} 10 \% \mathrm{SDS}$, protease inhibitors) and equal amounts of proteins $(20-50 \mu \mathrm{g})$ separated on $4-15 \%$ gradient SDSpolyacrylamide gels (BIO-RAD Laboratories, USA) before transferring to polyvinylidene fluoride (PVDF) membranes (Millipore Corp, Bedford, USA) and blocking with $5 \%$ skimmed milk powder in TBS-T (TBS $+0.1 \%$ Tween 20) for 60 min, PVDF membranes were washed three times with TBS/T and incubated with primary antibody at a 1:1000 dilution in TBS/T-5\% BSA overnight at $4{ }^{\circ} \mathrm{C}$. After washing with TBS/T, membranes were probed with goat anti-rabbit or anti-mouse IRDye (1:15000) (LI-COR Inc., Germany) at room temperature for $60 \mathrm{~min}$, washed with TBS/T and scanned using the Odyssey Imaging System (LI-COR Inc.).

\section{Real-time PCR quantification}

Reactions were performed using an Applied Biosystem 7000 Systems (Applied Biosystem) as described previously [11] using primers and probes specific to NQO1, GSTA1 and NFEL2 (Nrf2) (Sigma-Genosys, UK and Eurogentec Ltd, Southampton, UK) (Supplementary Methods).

\section{Confocal microscopy}

NB4, KG1a and HL60 cells were treated for $4 \mathrm{~h}$ and cytospins prepared before fixing with $4 \%$ paraformaldehyde. Slides were stained with an antiNrf2 (Abcam Ltd, UK) antibody diluted in PBS + 0.05\% Tween-20 (PBS/T) 
a

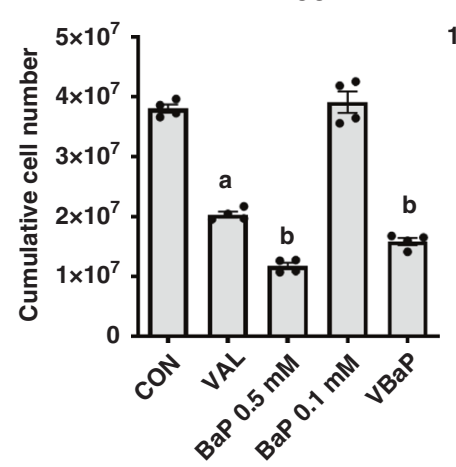

K562

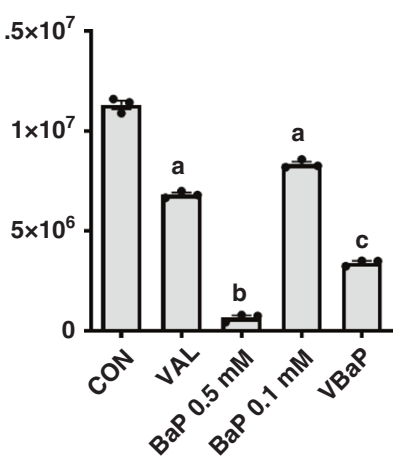

KG1a

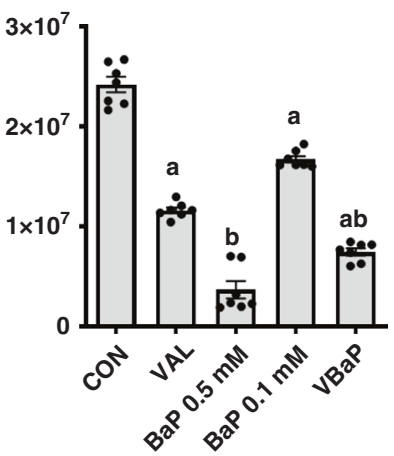

NB4
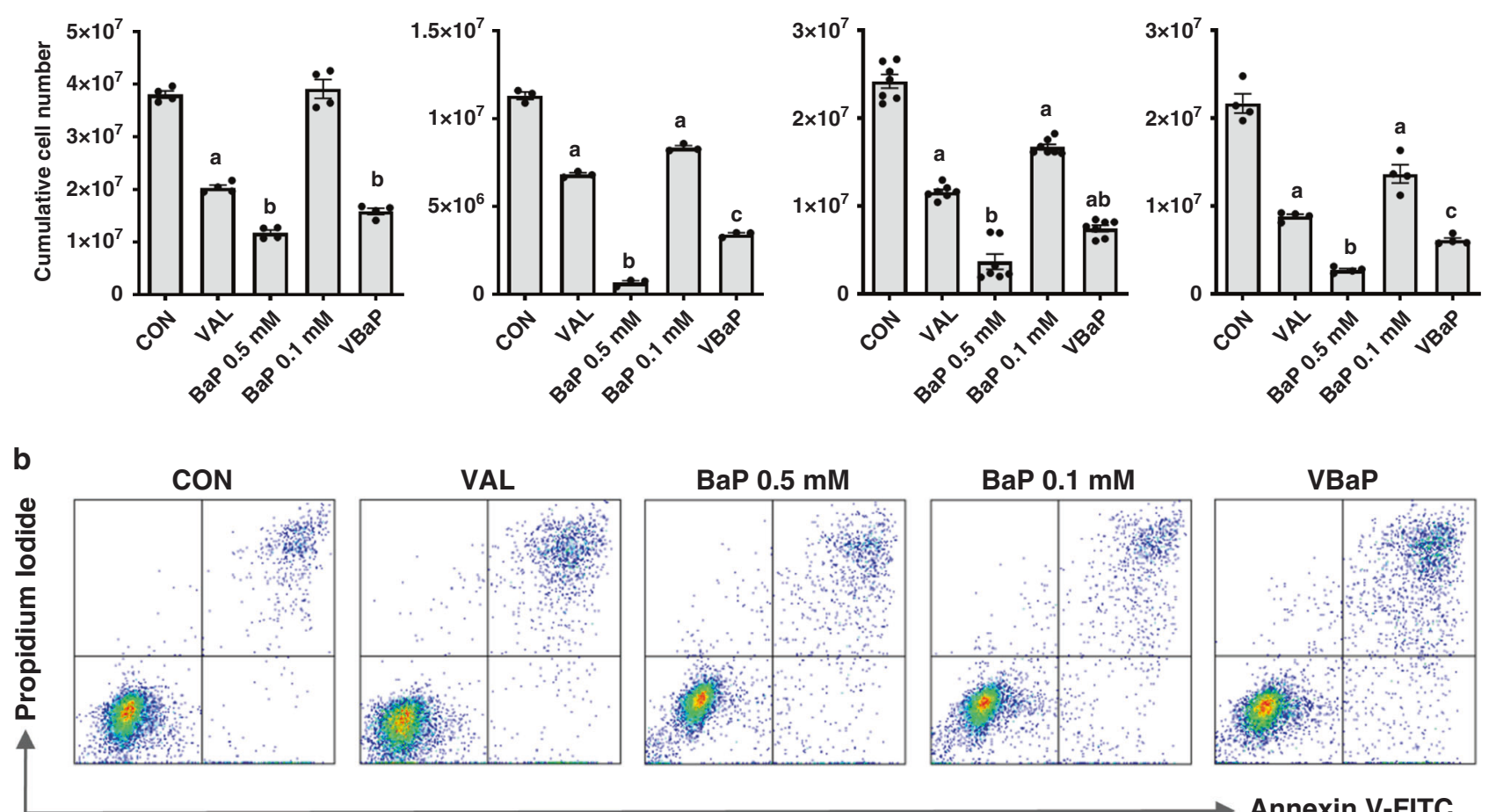

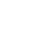



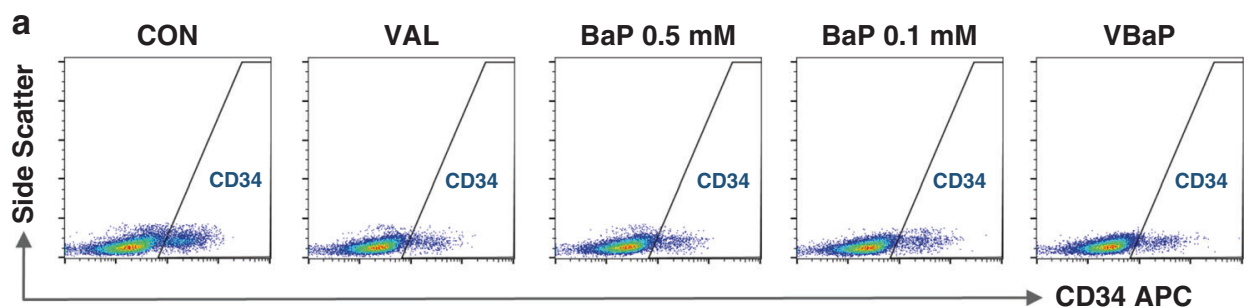

Primary AML Blast

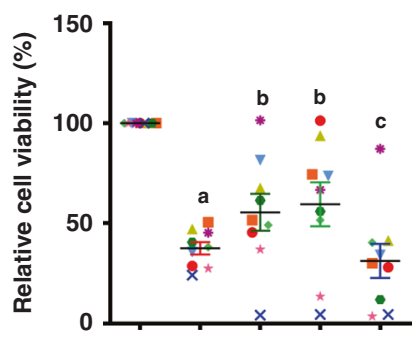

b

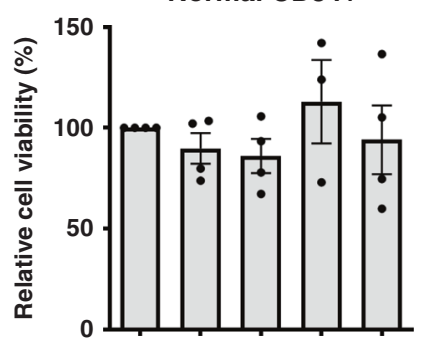

d

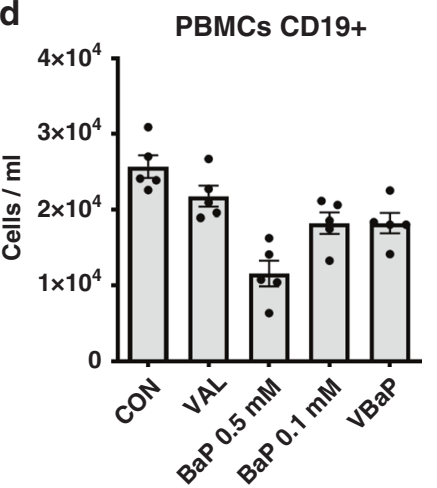

Primary AML non-Blast
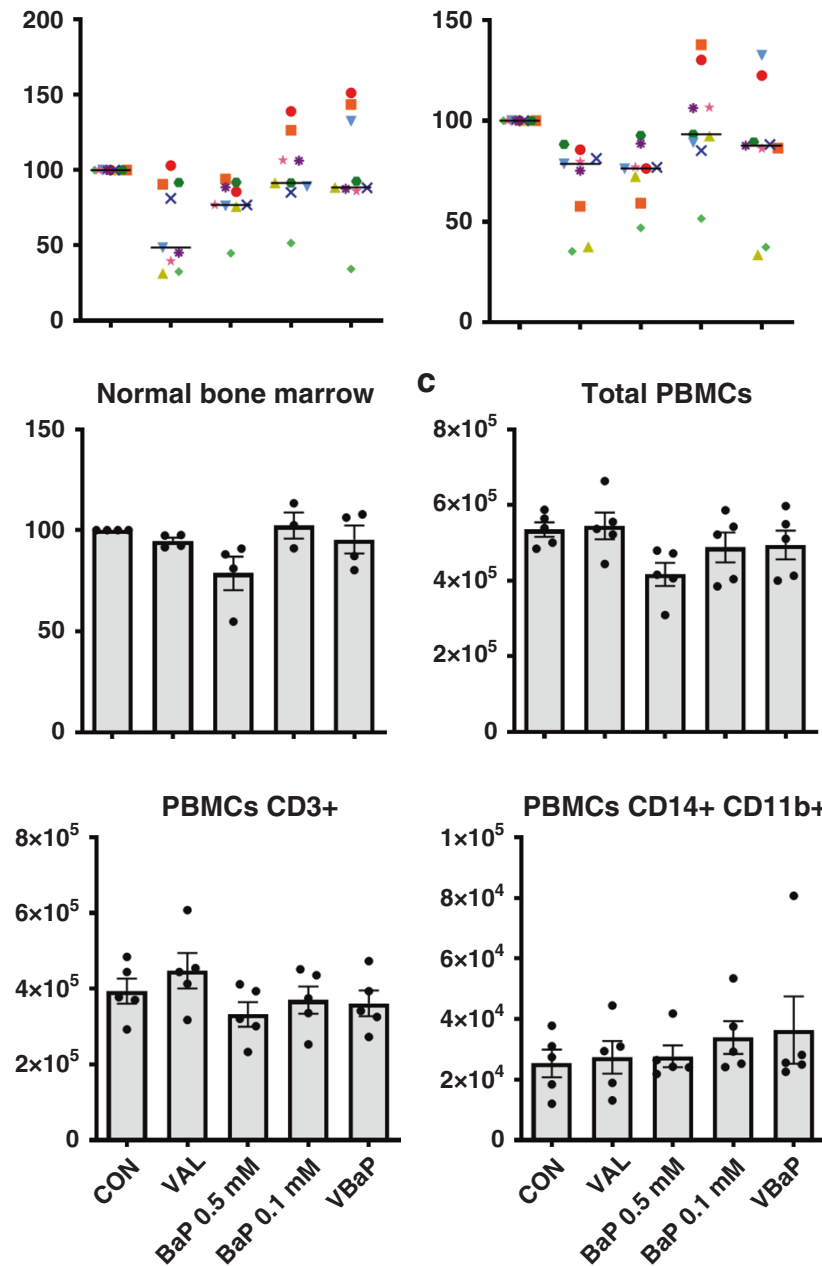

Primary AML total cells

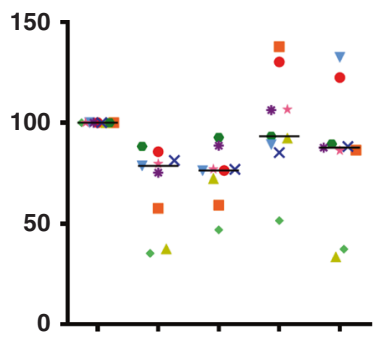

PBMCs CD14+ CD11b+

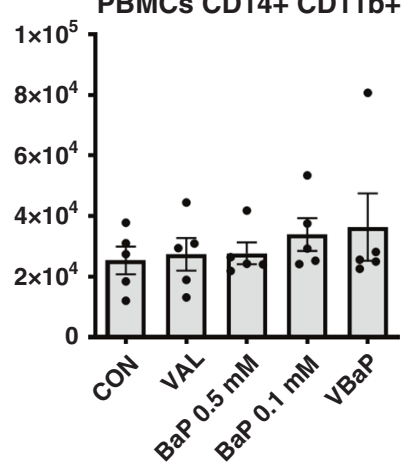

Fig. 2 VBaP kill primary AMLs but not normal healthy cells. a Primary AML samples were treated for 4 days and the viability of AML blast cells (positive for either CD34 and/or CD117), non-blast CD34- $/$ CD $117^{-}$cells and total cells were determined by flow cytometry. Horizontal bars represent the mean values of all samples. FACS plots show typical gating for $\mathrm{CD}_{3} 4^{+}$cells. Dot plots show individual sample viable cell counts normalised to each sample untreated control. b Normal donor bone marrows $(n=4)$ were treated for 4 days and total CD34 $4^{+}$cell number and total cell viability were determined by flow cytometry. (C\&D) PBMCs $(n=5)$ were purified from healthy donors and treated for 4 days. Survival of $\mathbf{c}$ total PBMCs, $\mathbf{d}$ B lymphocytes (CD19+), T lymphocytes (CD3+) and monocytes (CD14+CD11b+) were determined by flow cytometry with counting beads $(n=4)$. Bar charts shows mean \pm SEM. Different letters indicate significant difference from other treatment groups $(p<0.05)$. Abbreviations: vehicle control (CON), $0.6 \mathrm{mM}$ Valproic acid $(\mathrm{VAL}), 0.5 \mathrm{mM}$ BEZ and $5 \mu \mathrm{M} \mathrm{MPA}(\mathrm{BaP} 0.5 \mathrm{mM}), 0.1 \mathrm{mM}$ BEZ and 5 $\mu \mathrm{M}$ MPA (BaP 0.1 mM), the combination of Valproic acid $0.6 \mathrm{mM}$ and BaP $0.1 \mathrm{mM}(\mathrm{VBaP})$.

(Supplementary Fig. 1). The transposon plasmid contains a transposable cassette with the hygromycin resistance gene under CMV promoter and the polycistronic NRF2-EGFP genes linked with T2A self-cleaving 2A sequence under the EF1A promoter. EGFP control transposon plasmid was designed identically, but lacking the NRF2 gene and T2A sequence. The transposase plasmid transiently expresses the hyperactive version of piggyBac transposase (PBase) (Supplementary Fig. S1).

$5 \times 10^{6} \mathrm{~K} 562$ and KG1a cells were resuspended in $100 \mu$ l of Ingenio Transfection Solution (Mirus Bio LLC, Madison, WI, USA). Highly purified endotoxin free plasmids were added as follows: $1 \mu \mathrm{g}$ of PBase transposase plasmid and $1.5 \mu \mathrm{g}$ of either NRF2(T2A)EGFP or EGFP transposon plasmid. Cells were transfected with program U-008 using an Amaxa Nucleofector II (Lonza, Basel, Switzerland), resuspended in $3 \mathrm{ml}$ of warm complete media and incubated for $72 \mathrm{~h} . \mathrm{K} 562$ and KG1a transfected cells were then put under selection with $200 \mu \mathrm{g} / \mathrm{ml}$ or $300 \mu \mathrm{g} / \mathrm{ml}$ of Hygromycin B Gold (Invivogen, San Diego, CA, USA), respectively. Selection media was changed after $72 \mathrm{~h}$ and when needed. After 3 weeks under selection, stably transfected cells were sorted by GFP fluorescence by the University of Birmingham Flow cytometry facility, and polyclonal sorted cells expanded in hygromycin free media. 
a

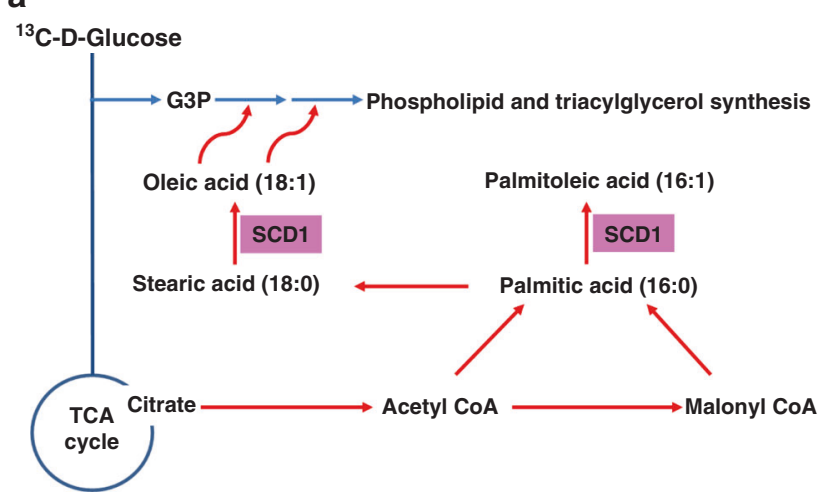

b

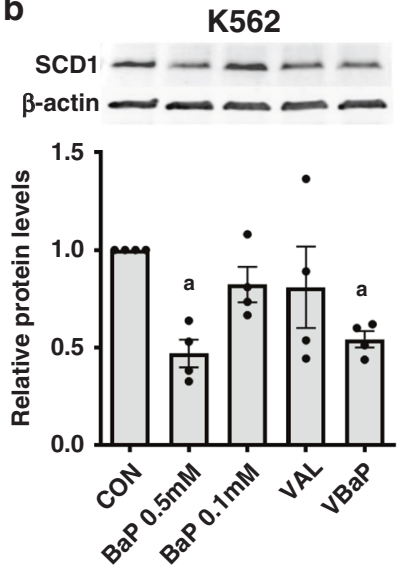

C
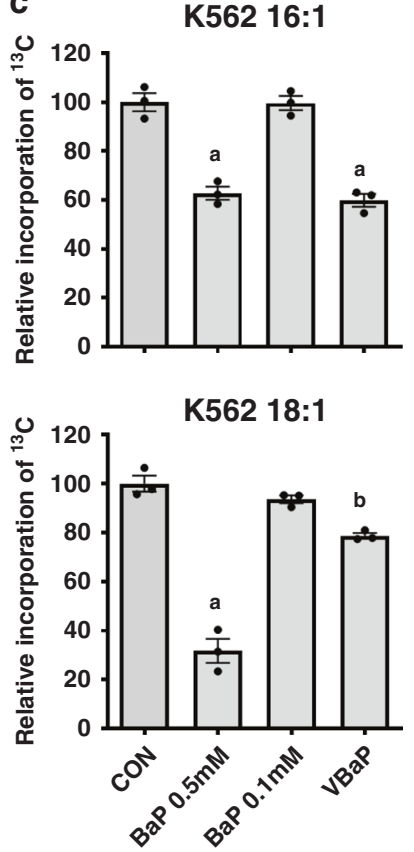

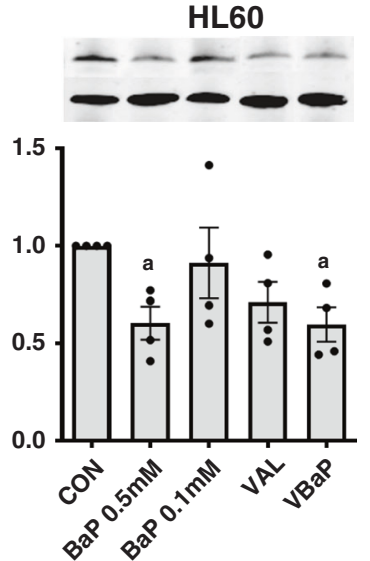

HL60 16:1
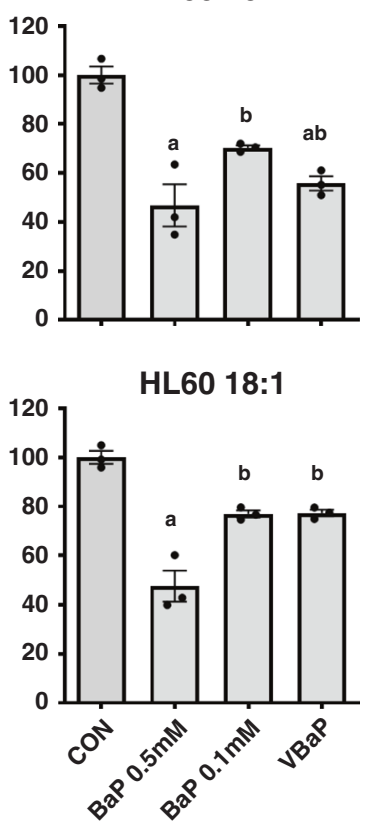

HL60 18:1

\section{Statistical analysis}

Unless stated otherwise, data were compared using one-way ANOVA with Tukey post-hoc test. Significance of $p<0.05$ is denoted by letters. Unique letters highlight statistical difference from the other treatment groups. Treatment groups with the same letter are not significantly different from each other.

Fig. 3 VBaP decreases SCD1 protein levels and activity in AML cell lines. a Schema showing role of SCD1 in monounsaturated fatty acid (MUFA) metabolism. b K562 and HL60 cells were treated for $72 \mathrm{~h}$ and protein levels of SCD1 determined using western blotting. Panels show representative images of western blots. Bar charts show mean \pm SEM densitometry data $(n=4)$. c K562 and HL60 cells were treated for $24 \mathrm{~h}$ and de novo MUFA synthesis from ${ }^{13} \mathrm{C}$-glucose determined using mass spectrometry. Data are shown as ${ }^{13} \mathrm{C}$ incorporation into palmitoleic acid (16:1) and oleic acid (18:1) relative to control $(n=3, \pm \mathrm{SEM})$. Different letters indicate significant difference from other treatment groups $(p<0.05)$. Abbreviations: vehicle control (CON), $0.6 \mathrm{mM}$ Valproic acid (VAL), $0.5 \mathrm{mM}$ BEZ and $5 \mu \mathrm{M}$ MPA (BaP 0.5 mM), $0.1 \mathrm{mM}$ BEZ and $5 \mu \mathrm{M}$ MPA (BaP $0.1 \mathrm{mM}$ ), the combination of Valproic acid $0.6 \mathrm{mM}$ and $\mathrm{BaP} 0.1 \mathrm{mM}(\mathrm{VBaP})$.

\section{RESULTS}

Valproic acid enhances anti-AML effect of low dose BaP

In order to enhance the anti-tumour efficacy of BaP, we screened our custom drug repurposing library (FMC) for an adjunctive agent that increased AML cell killing in the presence of low dose $\mathrm{BaP}$ (BaP $0.1 \mathrm{mM}$ ). This screen identified sodium valproate (sodium salt valproic acid-VAL) (data not shown) a commonly used oral antiepileptic agent which is generally very well-tolerated. Fig. 1a shows cell survival data for HL60, K562, KG1a and NB4 AML cell lines treated with vehicle control, VAL, high dose BaP $(0.5 \mathrm{mM}$ $\mathrm{BaP}), \mathrm{BaP} 0.1 \mathrm{mM}$ and $\mathrm{VBaP}(\mathrm{VAL}+\mathrm{BaP} 0.1 \mathrm{mM})$. As expected, cell killing by $\mathrm{BaP} 0.1 \mathrm{mM}$ in all four cell lines was inferior to killing in response to $\mathrm{BaP} 0.5 \mathrm{mM}$ (Fig. 1a). However, VAL alone and in combination with $\mathrm{BaP} 0.1 \mathrm{mM}(\mathrm{VBaP})$ enhanced cell killing when compared to BaP $0.1 \mathrm{mM}$ alone at day 7 (Fig. 1a).

VBaP-induced AML cell death was associated with Annexin V (AV) positivity, a marker associated with apoptosis (Fig. 1b). In NB4 and $\mathrm{HL} 60$ cells, VBaP induced greater AV positivity than BaP 0.5 $\mathrm{mM}$ whereas in $\mathrm{K} 562$ and $\mathrm{KG} 1 \mathrm{a}$ they were slightly lower. VAL alone increased AV positivity in all cell lines, and in HL60 cells generated higher AV expression than BaP 0.5 mM (Fig. 1b).

Importantly, the combined activity of VBaP compared to either drug alone was not restricted to $A M L$ cell lines and was recapitulated against primary $\mathrm{AML}$ samples $(N=9)$ (Fig. 2a). In particular, VAL alone and VBaP had increased activity against AML blasts when compared to either $\mathrm{BaP} 0.5 \mathrm{mM}$ or $\mathrm{BaP} 0.1 \mathrm{mM}$ (Fig. 2a). In contrast, drug treatments demonstrated variable, but non-significant effects on the non-blast cells in AML samples (Fig. 2a) and this was reflected in total AML cell numbers (Fig. 2a). These data indicate that within AML bone marrow samples, our drugs specifically target the tumour blast cells. This was further supported by data from healthy donor samples. VBaP induced no significant loss in viability in samples from healthy donors including bone marrow derived $\mathrm{CD}_{3} 4^{+\mathrm{ve}}$ hematopoietic stem/ progenitor cells (HSPC) or total bone marrow cells (Fig. 2b), total peripheral blood mononuclear cell (PBMC) preparations (Fig. 2c), or $B$ cell $(C D 19+)$, T-cell $(C D 3+)$ or myeloid cell fractions $(\mathrm{CD} 14+\mathrm{CD} 11 \mathrm{~b}+)$ within PBMCs (Fig. 2d).

\section{VBaP reduces SCD1 protein levels and activity}

Stearoyl-CoA desaturase-1 (SCD1) is a key enzyme in fatty acid metabolism, catalysing the rate-limiting step in the formation of monounsaturated fatty acids (MUFAs), specifically oleic acid (18:1) and palmitoleic acid (16:1) from stearic acid (18:0) and palmitic acid (16:0) (Fig. 3a) [15]. We previously reported that BaP $0.5 \mathrm{mM}$ can disrupt the SCD1-mediated synthesis of MUFAs in AML cells and that this was mediated, in part, by BaP downregulating SCD1 protein levels [6]. BaP $0.5 \mathrm{mM}$ again reduced SCD1 protein levels in $\mathrm{K} 562$ and HL60 cells however, BaP $0.1 \mathrm{mM}$ and VAL alone did not (Fig. 3b). In contrast, addition of VAL to BaP $0.1 \mathrm{mM}$ reduced SCD1 protein levels to a similar level as BaP $0.5 \mathrm{mM}$ in both $\mathrm{K} 562$ and HL60 (Fig. 3b). 
a

KG1a ROS

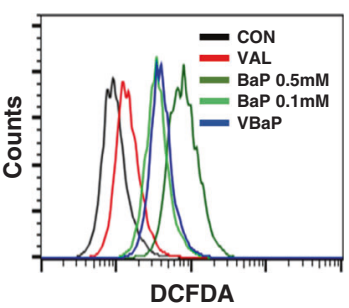

24 h NB4 ROS

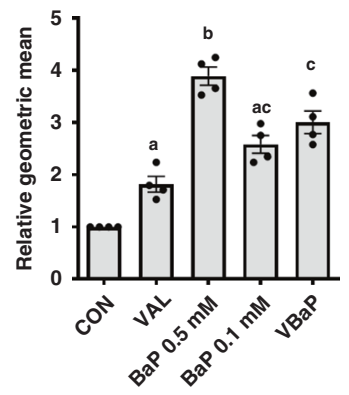

b

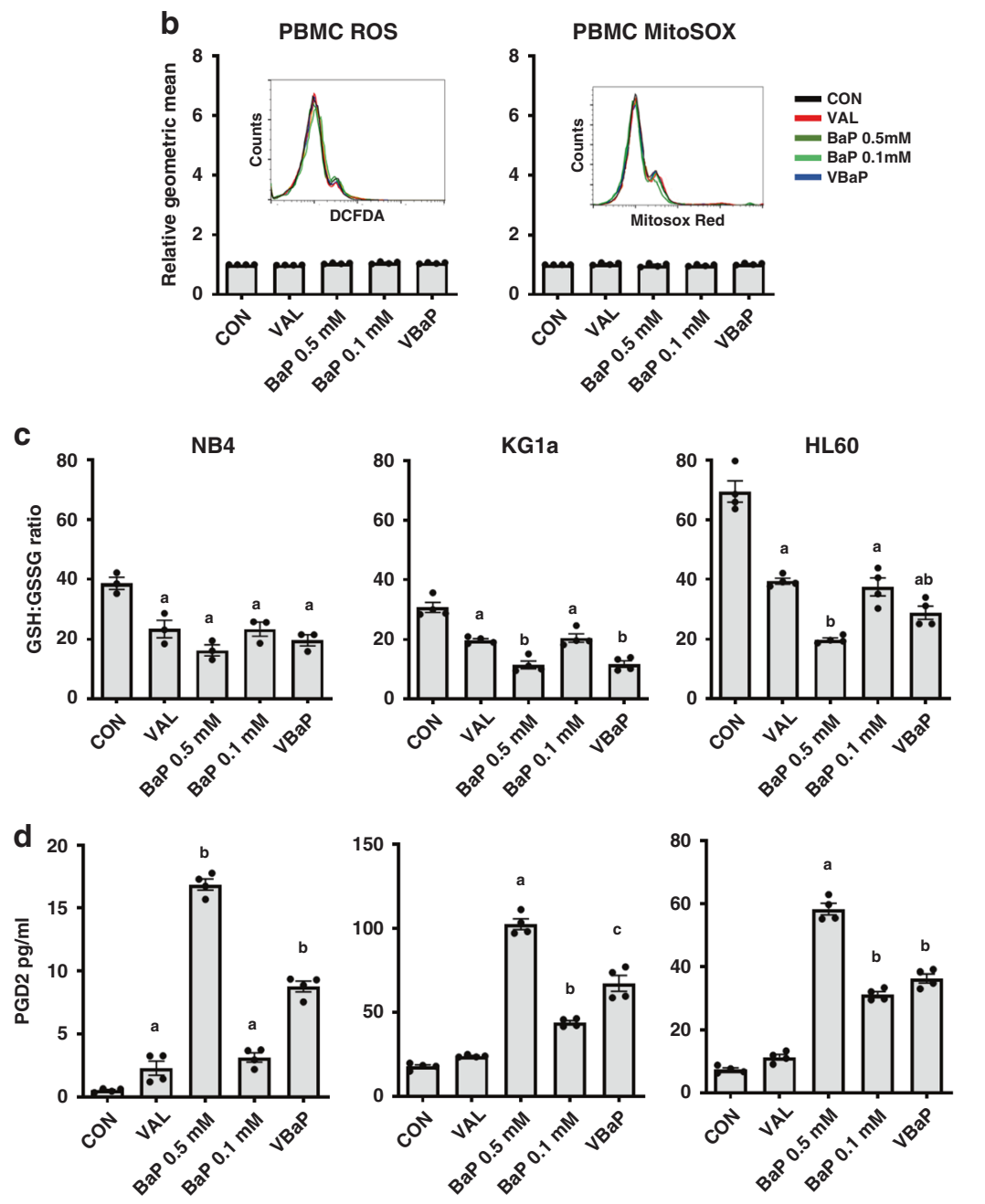

24 h KG1a ROS

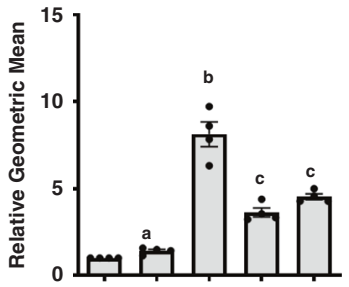

24 h HL60 ROS

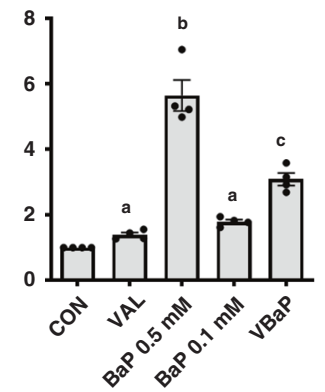

72 h KG1a ROS

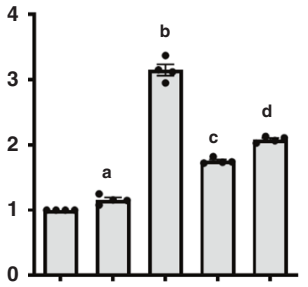

72 h K562 ROS

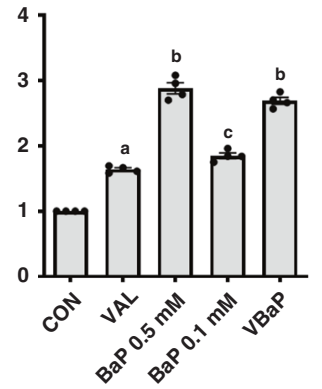

As previously reported [6], mass spectrometry lipidomics analysis after $24 \mathrm{~h}$ exposure to ${ }^{13} \mathrm{C}$-glucose identified that $\mathrm{BaP}$ $0.5 \mathrm{mM}$ reduced both palmitoleic acid (C16:1) and oleic acid (C18:1) synthesis, an observation consistent with reduced SCD1 levels (Fig. 3c). BaP $0.1 \mathrm{mM}$ had no effect on ${ }^{13} \mathrm{C}$-incorporation into C16:1 and C18:1 in K562, whereas a small reduction was observed in HL60 cells. VBaP treatment drove down C16:1 levels in both cell lines to a level similar to BaP $0.5 \mathrm{mM}$ however, the impact of $\mathrm{VBaP}$ 
Fig. 4 VBaP induced ROS generation in AML cells but not PBMCs. a KG1a, NB4, HL60 and K562 cells were treated for 24 or $72 \mathrm{~h}$, stained with carboxy- $\mathrm{H}_{2}$ DCFDA for the detection of ROS and analysed by flow cytometry. Flow cytometry histograms show representative ROS data after $24 \mathrm{~h}$ treatment for KG1a cells; bar charts show mean data \pm SEM from $n=4$ experiments at $24 \mathrm{~h}$ for KG1a, NB4 and HL60, and at $72 \mathrm{~h}$ for KG1a and K562. b PBMCs from healthy donors were treated as shown for $24 \mathrm{~h}$, stained with MitoSOX Red and carboxy- $\mathrm{H}_{2}$ DCFDA and analysed by flow cytometry. Flow cytometry histograms show representative data; bar charts show mean \pm SEM data from $n=4$ donors. NB4, KG1a and HL60 cells were treated for $6 \mathrm{~h}$ before quantification of c reduced glutathione: oxidised glutathione (GSH:GSSG) ratios using the GSH/GSSGGlo $^{\mathrm{TM}}$ Assay (see 'Methods') and $\mathbf{d}$ Prostaglandin D2 (PGD2) by ELISA. Data are mean \pm SEM for $n=4$ experiments. Different letters indicate significant difference from other treatment groups $(p<0.05)$. Abbreviations: vehicle control $(C O N), 0.6 \mathrm{mM}$ Valproic acid $(\mathrm{VAL}), 0.5 \mathrm{mM}$ BEZ and $5 \mu \mathrm{M}$ MPA (BaP $0.5 \mathrm{mM}), 0.1 \mathrm{mM}$ BEZ and $5 \mu \mathrm{M}$ MPA (BaP $0.1 \mathrm{mM}$ ), the combination of Valproic acid $0.6 \mathrm{mM}$ and BaP $0.1 \mathrm{mM}(\mathrm{VBaP})$.

on C18:1 levels was less marked (Fig. 3c). All these data demonstrate that at $24 \mathrm{~h} \mathrm{VBaP}$ targets SCD1 and palmitoleic acid (16:1) levels in AML cells.

\section{VAL enhanced the ROS generation in AMLs}

We have previously shown that $A M L$ cell killing by BaP $0.5 \mathrm{mM}$ is directly related to the generation of reactive oxygen species (ROS) [11]. Thus it was important to investigate ROS production in the context of VBaP. As shown in Fig. 4a, BaP $0.5 \mathrm{mM}$ treatment induced consistently higher ROS in HL60, KG1a, NB4 and K562 AML cells compared to all other treatments (Fig. 4a). However, $\mathrm{VBaP}$ consistently produced the next highest ROS production in all three AML cell lines at $24 \mathrm{~h}$ (Fig. 4a). VBaP also consistently induced greater ROS when measured at either $24 \mathrm{~h}$ or $72 \mathrm{~h}$ than either VAL or $\mathrm{BaP} 0.1 \mathrm{mM}$ alone (Fig. 4a). In contrast to ROS, mitochondrial superoxide (mitosox) levels in NB4, KG1a and HL60 cells were largely unchanged in response to any of the treatments (Supplementary Fig. S2). Critically, no ROS or mitosox generation was seen in normal donor derived PBMCs in response to any of the treatments (Fig. 4b).

\section{VBaP induces oxidative stress in AMLs}

During oxidative stress, the ratio of reduced glutathione (GSH) and oxidised glutathione (GSSG) levels decreases as cells attempt to moderate the damage caused by ROS [16]. We previously showed that ROS and prostaglandin production by $\mathrm{BaP} 0.5 \mathrm{mM}$ resulted in depletion in cellular glutathione levels [11]. We, therefore, measured total glutathione and also GSH and GSSG individual levels (Supplementary Fig. S3) before and after treatments. Consistent with generation of ROS, BaP $0.5 \mathrm{mM}, \mathrm{BaP} 0.1 \mathrm{mM}, \mathrm{VAL}$ and VBaP reduced GSH levels with $\mathrm{BaP} 0.5 \mathrm{mM}$ and $\mathrm{VBaP}$ having the most effect (Supplementary Fig. S3). GSH:GSSG ratios (Fig. 4c) were significantly reduced with all drug treatments addition of $V A L$ to $B a P$ $0.1 \mathrm{mM}$ reducing the GSH:GSSG ratios to levels similar to that induced by BaP $0.5 \mathrm{mM}$ in all AML cell lines tested.

\section{VBaP impacts lipid peroxidation and downstream prostaglandin synthesis in AML cells}

Oxidative stress and ROS also activates the lipid peroxidation pathway [17]. We previously demonstrated that BaP $0.5 \mathrm{mM}$ elevates lipid peroxidation in AML cells and that this leads to the downstream cyclooxygenase-independent generation and accumulation of $\mathrm{PGD}_{2}$ [11]. The rationale behind this observation was that BEZ driven ROS production caused lipid peroxidation and downstream generation of $\mathrm{PGD}_{2}$, and that simultaneously, MPA inhibits the metabolism of $\mathrm{PGD}_{2}$ by the aldoketoreductase AKR1C3 [18-20]. As shown in Supplementary Fig. 4A, BaP $0.5 \mathrm{mM}$ again induced significant lipid peroxidation in all three cell lines tested. The reduction in lipid peroxidation was less with $\mathrm{BaP} 0.1 \mathrm{mM}$, and enhanced only marginally by the addition of Val (VBaP) in any of the lines (Supplementary Fig. S4A). These observations are consistent with and correlate with the relative generation of ROS by these treatments shown in Fig. 4a.

Analysis of $P G D_{2}$ levels by ELISA highlighted variable basal levels between NB4, KG1a and HL60 cell lines (Fig. 4d). Consistent with its higher induction of ROS and lipid peroxidation, BaP $0.5 \mathrm{mM}$ treatment led to the greatest increases in $\mathrm{PGD}_{2}$ production in all the lines (Fig. 4d). However, BaP 0.1 mM also significantly increased $\mathrm{PGD}_{2}$ production in all three cell lines which was significantly increased by the addition of VAL (Fig. 4d). VAL alone did not significantly increase $\mathrm{PGD}_{2}$ production in KG1a cells or HL60 cells, whereas a small increase was seen in NB4 cells (Fig. 4d). We have previously demonstrated that in $A M L$ cells the $P G D_{2}-11$-ketoreductase activity of AKR1C3 metabolises $P_{G D}$ to form $11 \beta-P_{2} F_{2} a$. When not metabolised by $A K R 1 C 3, \mathrm{PGD}_{2}$ undergoes a series of spontaneous dehydration reactions to form the anti-neoplastic and highly electrophilic derivative 15 deoxy $\Delta^{12,14}-\mathrm{PGJ}_{2} \quad\left(15 \mathrm{~d}-\mathrm{PGJ} \mathrm{J}_{2}\right)$ $[21,22]$. As observed for $P G D_{2}$ levels, $15 d-P G J_{2}$ production in response to $\mathrm{VBaP}$ was significantly increased in NB4 and KG1a when compared to $\mathrm{BaP} 0.1 \mathrm{mM}$ and again there was a trend towards an increase in HL60 cells (Supplementary Fig. S4B).

Thus, we demonstrate that the relative induction of ROS by our drug treatments coincide with glutathione depletion, lipid peroxidation and prostaglandin synthesis with addition of VAL to BaP $0.1 \mathrm{mM}$ restoring levels closer to $\mathrm{BaP} 0.5 \mathrm{mM}$ in all the cell lines tested.

\section{VBaP enhances ROS mediated damage by inhibiting Nrf2 function}

Under conditions of oxidative stress, Nuclear factor erythroid 2-related factor 2 (Nrf2), the master transcriptional regulator of antioxidant response genes, translocates to the nucleus and activates its own expression as well as other key antioxidant genes. Consistent with ROS production, $\mathrm{BaP} 0.5 \mathrm{mM}$ induced small increases in total Nrf2 levels in HL60, KG1a or NB4 cells and a significant increase in K562 cells (Fig. 5a). Despite inducing ROS, albeit at lower levels than $\mathrm{BaP} 0.5 \mathrm{mM}, \mathrm{BaP} 0.1 \mathrm{mM}$ did not alter total Nrf2 protein levels. In marked contrast, VAL and VBaP exposure significantly reduced total Nrf2 protein levels in all four AML cell lines (Fig. 5a). Furthermore, western blots of nuclear protein extracts identified that, whereas both doses of $\mathrm{BaP}$ increased nuclear Nrf2 levels, VAL and VBaP did not significantly alter nuclear translocation of Nrf2 (Fig. 5b). This ability of VAL to suppress nuclear translocation of $\mathrm{Nrf2}$ was confirmed using immunofluorescence staining of HL60 and NB4 cells. As shown in Fig. 5c for NB4, the addition of VAL alone reduced nuclear translocation of Nrf2 compared to untreated controls and similarly VBaP decreased nuclear localisation of Nrf2 compared to either BaP $0.5 \mathrm{mM}$ or BaP $0.1 \mathrm{mM}$. Similar data were obtained for HL60 (Supplementary Fig. S5).

Finally, we used qRT-PCR to measure transcription levels of NFE2L2 which encodes for Nrf2, and the Nrf2 target genes NAD(P) $\mathrm{H}$ dehydrogenase [quinone] 1 (NQO1) and glutathione S-transferase A1 (GSTP1) [23]. Consistent with increased nuclear trafficking of Nrf2 and transcriptional activity, both BaP $0.5 \mathrm{mM}$ and BaP $0.1 \mathrm{mM}$ increased expression of NFE2L2 and GSTA1 mRNA in NB4, KG1a and HL60 cells (Fig. 5d and Supplementary Fig. S6). NQO1 mRNA levels were increased with BaP $0.5 \mathrm{mM}$ in all three cell lines, and in BaP $0.1 \mathrm{mM}$ treated NB4 and KG1a cells but not HL60 cells (Fig. $5 \mathrm{~d}$ and Supplementary Fig. S4). The addition of VAL to BaP $0.1 \mathrm{mM}$ attenuated this transcriptional response to oxidative stress in all three cell lines (Fig. $5 \mathrm{~d}$ and Supplementary Fig. S6). Thus, these data indicate that VAL sensitises AML cells to BaP $0.1 \mathrm{mM}$ by inhibiting Nrf2. 
a

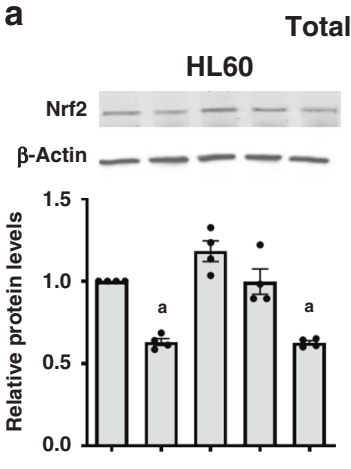

Total protein

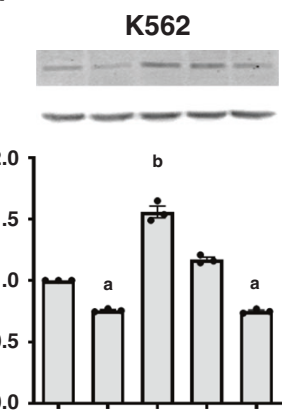

KG1a

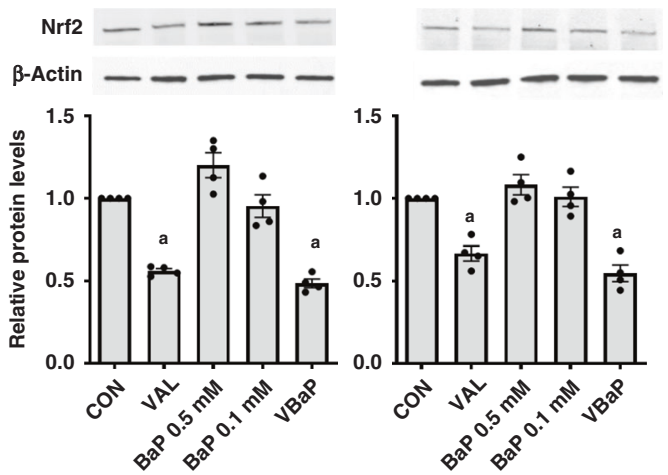

C
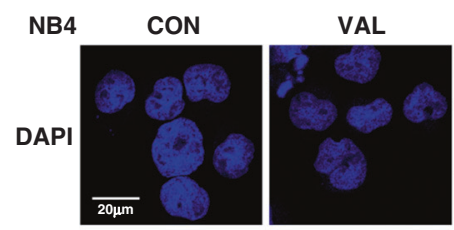

Nrf2
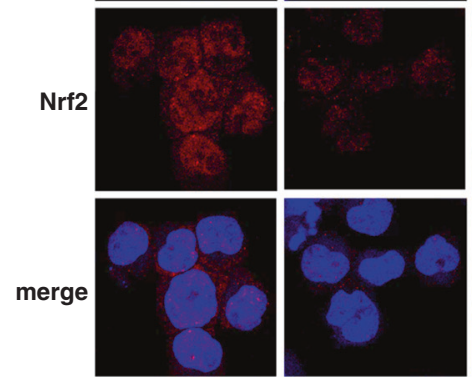

d
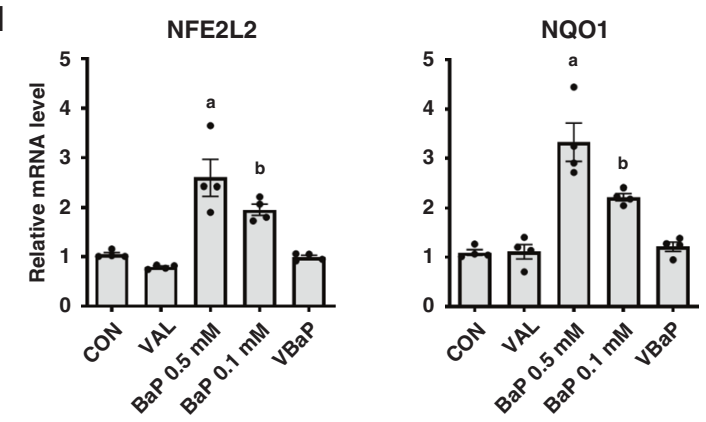
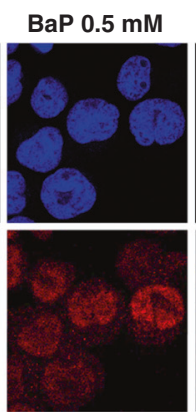

b Nuclear protein
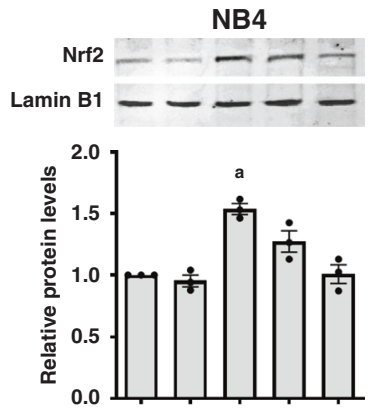

HL60
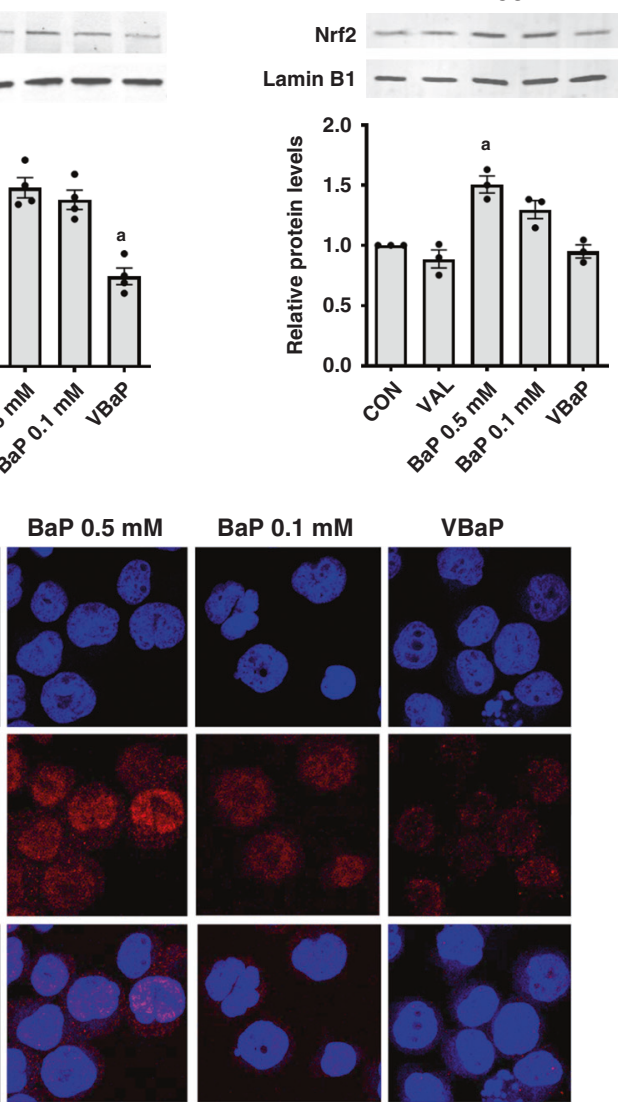

GSTA1

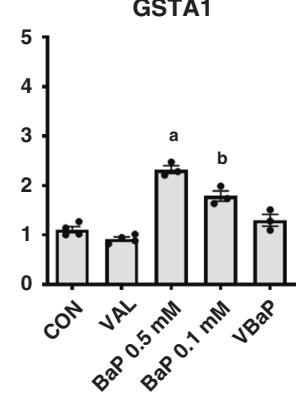

Overexpression of Nrf2 abrogates the ability of VAL to enhance BAP $0.1 \mathrm{mM}$ AML cell responses

In order to confirm the role of VAL-mediated suppression of Nrf2 responses in potentiating responses to $\mathrm{BaP} 0.1 \mathrm{mM}$, we constitutively expressed Nrf2 in $\mathrm{K} 562$ and KG1a AML. As previously observed for WT cells (Fig. 5a), Nrf2 protein expression was also reduced by VAL and $\mathrm{VBaP}$ compared to controls and $\mathrm{BaP} 0.1 \mathrm{mM}$ in EGFP vector control transfectants of both $\mathrm{K} 562$ and $\mathrm{KG1a}$ (Fig. 6a). In contrast, Nrf2 levels did not reduce in Nrf2overexpressing $\mathrm{K} 562$ and KG1a cells (Fig. 6a). As observed for wild type (WT) cells (Figs. 1a and 6b), VAL and VBaP enhanced killing of K562- and KG1a-EGFP empty vector control cells as 
Fig. 5 VBaP downregulates Nrf2 protein induction and activity. a HL60, K562, KG1a and NB4 cells were treated as shown for $4 \mathrm{~h}$ and protein levels of Nrf2 determined using western blotting using $\beta$-actin as a loading control. Panels show representative images of blots. Bar charts show total Nrf2 protein levels (normalised to $\beta$-actin) relative to control as mean \pm SEM from $n=3$ experiments. b NB4, and HL60 cells were treated as shown for $4 \mathrm{~h}$ and nuclear proteins extracted and immunoblotted for Nrf2 with Lamin B1 as a loading control. Panels show representative images of blots. Bar charts show relative nuclear Nrf2 protein levels (normalised to Lamin B levels) expressed as means \pm SEM from $n=3$ experiments. c NB4 cells were treated as shown for $4 \mathrm{~h}$ and cytospins prepared before fixing with paraformaldehyde and immunostaining staining for Nrf2 (red) and counterstaining nuclei with DAPI (blue). Scale bar indicates $20 \mu \mathrm{m}$. d NB4 cells were treated as shown for $4 \mathrm{~h}$ before extracting total RNA and synthesising CDNA. qRT-PCR was performed using gene-specific primers to Nrf2 target genes NFE2L2 (Nrf2), NAD(P)H dehydrogenase-quinone 1 (NQO1) and Glutathione S-transferase A1 (GSTA1). Data were normalised to 18s rRNA and calculated as relative mRNA compared to solvent controls. Bar charts show means \pm SEM from $n=3$ experiments. Different letters indicate significant difference from other treatment groups $(p<0.05)$. Abbreviations: vehicle control $(\mathrm{CON}), 0.6 \mathrm{mM}$ Valproic acid $(\mathrm{VAL}), 0.5 \mathrm{mM} B E Z$ and $5 \mu \mathrm{M}$ MPA (BaP 0.5 mM), 0.1 mM BEZ and $5 \mu \mathrm{M}$ MPA (BaP 0.1 mM), the combination of Valproic acid 0.6 mM and BaP $0.1 \mathrm{mM}(\mathrm{VBaP})$.

compared to untreated controls and BaP $0.1 \mathrm{mM}$ treated cells, respectively. In marked contrast, Nrf2 overexpression in KG1a and K562 cells completely rescued cells from VAL, BaP $0.1 \mathrm{mM}$ and VBaP induced killing (Fig. 6b). Killing by BaP $0.5 \mathrm{mM}$ was also almost completely rescued by overexpression of Nrf2 (Fig. 6b).

Similarly, as observed in WT cells (Figs. 4a and 6c), VAL and VBaP enhanced ROS production in EGFP empty vector control K562 and KG1a cells compared to untreated controls and $\mathrm{BaP} 0.1 \mathrm{mM}$ treated cells respectively (Fig. $6 \mathrm{c}$ ). In marked contrast, neither VAL nor VBaP induced ROS production in constitutively Nrf2overexpressing $\mathrm{K} 562$ and KG1a cells and ROS induction by BaP $0.5 \mathrm{mM}$ was significantly attenuated (Fig. 6a, b). Finally, constitutive expression of Nrf2 in KG1a cells also negated the capacity of $\mathrm{VBaP}$ to attenuate NQO1 and GSTA1 Nrf2-target genes compared to BAP $0.5 \mathrm{M}$ treatment in either WT or EGFP empty vector control cells (Fig. 6d). Similarly, constitutive expression of Nrf2 in K562 cells negated the capacity of VBaP to attenuate GSTA1 Nrf2-target genes compared to BAP $0.5 \mathrm{mM}$ in EGFP empty vector control cells. A similar, albeit statistically not significant, trend was observed for NQO1 expression in K562 cells.

\section{DISCUSSION}

This is a preclinical study addressing the failure to safely escalate $\mathrm{BaP}$ doses in $\mathrm{AML}$ patients in our most recent trial (ISRCTN99131400) compared to our first trial that showed efficacy and safety of continuous low dose BaP in elderly/relapsed AML (ISRCTN50635541) for sustained periods without complete remissions $[10,12]$. We have shown here that the addition of clinically achievable doses of VAL to low dose BaP $0.1 \mathrm{mM}$ (VBaP) recapitulates the killing of primary $A M L$ cells and $A M L$ cell lines seen in response to $\mathrm{BaP} 0.5 \mathrm{mM}$. Importantly, as expected for drugs that have been used safely in the clinic for decades, VBaP was tumour-selective with no loss in viability observed in normal donor PBMCs and bone marrow-derived HSPCs.

Whilst elucidating the mechanism of action of $\mathrm{BaP}$ in earlier studies, we had previously identified that $\mathrm{BaP}$ and $\mathrm{BEZ}$ suppressed de novo fatty acid synthesis by downregulating SCD1, a key ratelimiting enzyme involved in synthesising palmitoleic acid (16:1) and oleic acid (18:1), essential precursors for intracellular free fatty acid synthesis. As expected, BaP $0.1 \mathrm{mM}$ had less effect than $\mathrm{BaP}$ $0.5 \mathrm{mM}$ in lowering SCD1 levels, however, the addition of VAL was able to restore this activity (Fig. 3). Reductions in SCD1 were also reflected in similar patterns in changes in 16:1 and 18:1 fatty acid levels with VBaP. In another study, changes in fatty acid pathways were also identified by untargeted serum metabolomic profiling in 44 AML patients receiving ATRA and VAL combined with low-dose cytotoxic drugs (cytarabine, hydroxyurea, 6-mercaptopurin) [24]. Twenty-three metabolites, the majority associated with fatty acid metabolism and amino acid pathways, were significantly altered by seven-day valproic acid treatment [24]. VAL has also been demonstrated to alter key genes involved in adipogenesis, including reductions in SCD1 mRNA and protein expression, in 3T3-L1 cells induced to differentiate into adipocytes [25].
ROS are important regulators of cellular signalling in both physiological and pathological cellular processes and are elevated in many cancers including AML $[14,26,27]$ and MDS $[28,29]$. The cytotoxicity of many anti-AML therapies, e.g. cytarabine and daunorubicin in AML [30] is mediated at least in part by induction of ROS. Nrf2 is a master regulator of oxidative stress regulating expression of genes involved in neutralising ROS and aberrant Nrf2 activity has been shown to contribute to development, progression and chemotherapy resistance in multiple cancers including AML [31,32]. VAL has been shown to suppress Nrf2 expression in multiple cancers, sensitising them to oxidative stress [33-35]. We demonstrate here that this is also the case in AML cells. We have previously shown that oxidative stress is induced in a dose-dependent manner by BEZ in BaP and ROS levels correlate with killing in AML cells [11]. Hence, whilst BaP $0.1 \mathrm{mM}$ induces lower levels of ROS than BaP $0.5 \mathrm{mM}$, attenuation of the Nrf2 response by VAL in $\mathrm{VBaP}$ restores the cellular effects of $\mathrm{BaP} 0.1$ $\mathrm{mM}$ to almost BaP $0.5 \mathrm{mM}$ levels including lipid peroxidation, GSH: GSSG levels and ratios and $\mathrm{PGD}_{2}$ and $15 \mathrm{dPGJ}_{2}$ levels. Importantly, whilst AML cells were highly susceptible to $\mathrm{BaP}$ and $\mathrm{VBaP}$ induced ROS, normal donor PBMCs and HSPCs were resistant. Hence, VBaP induces oxidative stress in a tumour-selective manner.

Several trials have investigated VAL as adjunctive therapy in AML alongside ATRA, decitabine, theophylline or azacytidine $[11,36-38]$. These trials used VAL at doses higher than typically used in the management of epilepsy. At these high doses, VAL exhibits histone deacetylase activity but is also associated with adverse events in $A M L$ patients $[39,40]$. In vitro studies experiments have demonstrated variable dose-dependent responses to VAL $[41,42]$. Here, we have demonstrated an alternative mode of action for VAL in AML cells that can be exploited at lower VAL doses. Whilst, there are many factors influencing the clinical suitability and pharmacokinetics of VAL, serum concentrations of VAL consistent with our study are achievable in elderly patients using well-tolerated doses [43, 44] and we propose that clinical studies of $\mathrm{VBaP}$ are relevant and warranted.

A major challenge in our previous BaP trials has been the focus on elderly, relapsed/refractory AML patients for whom more intensive therapies were not option. Prognosis for these types of patients is very poor with a median survival of 7 weeks and consistent with this, 5/20 patients died within four weeks of commencing therapy. Despite this, we still managed to achieve sustained haematological responses using low dose $\mathrm{BaP}$ [10]. Therefore, we would propose that treating patients earlier in their disease progression with low toxicity therapies is the most effective clinical strategy for improving patient outcomes.

Approximately $10 \%$ of AML arises from transformation of MDS. Like AML, MDS are a heterogeneous group of myeloid neoplasms with diverse clinical courses. For many of these patients there are very few treatment options other than regular transfusions to combat life-threatening deficits in red cells and platelets and antibiotic control of frequent life threatening infections. It is therefore an attractive option to consider testing VBaP in MDS 
a

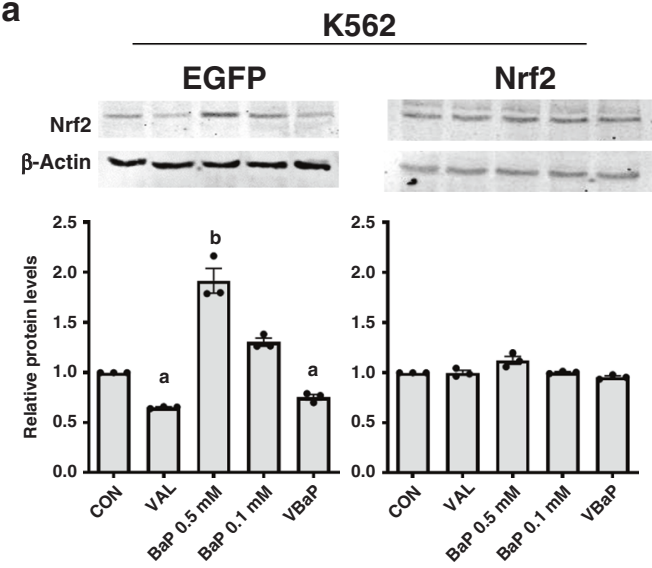

b

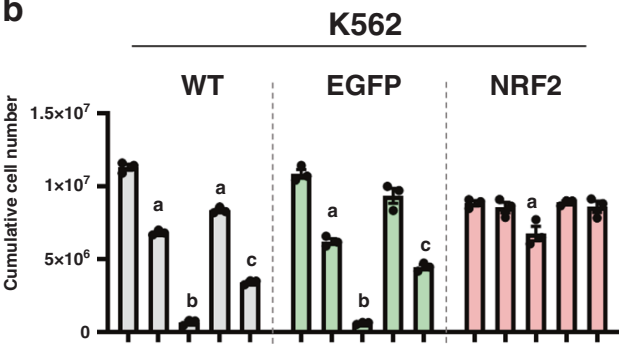

C

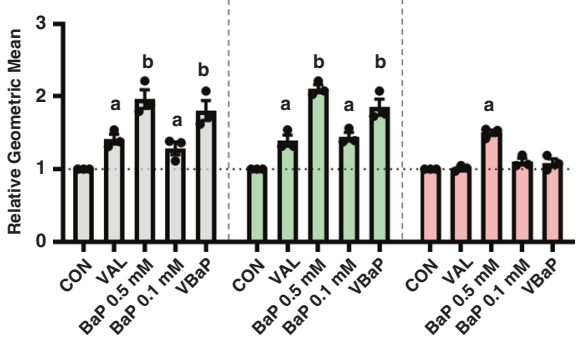

d
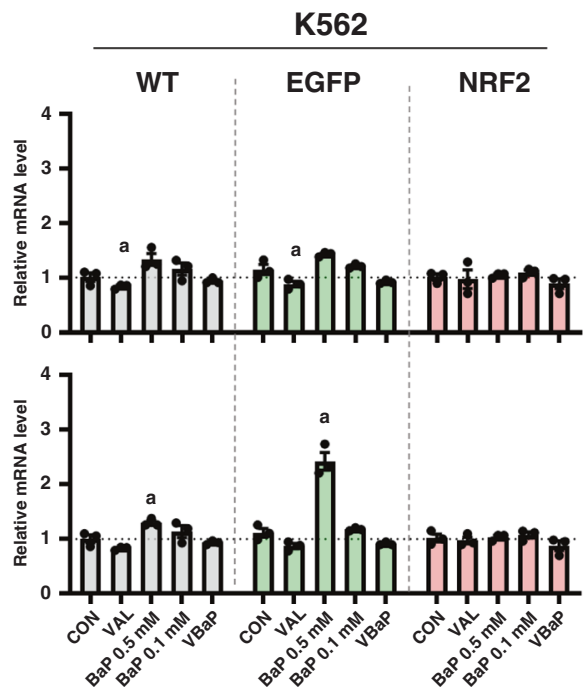

patients. The episodes of improved erythrocyte, platelet and neutrophil counts and diminished transfusion dependency observed in AML patients in our first trial [10] would represent real clinical benefit in MDS patients. In addition, the anti-AML activity of $\mathrm{VBaP}$ demonstrated here may delay and/or reduce transformation rates to AML. Thus, VBaP may have profound
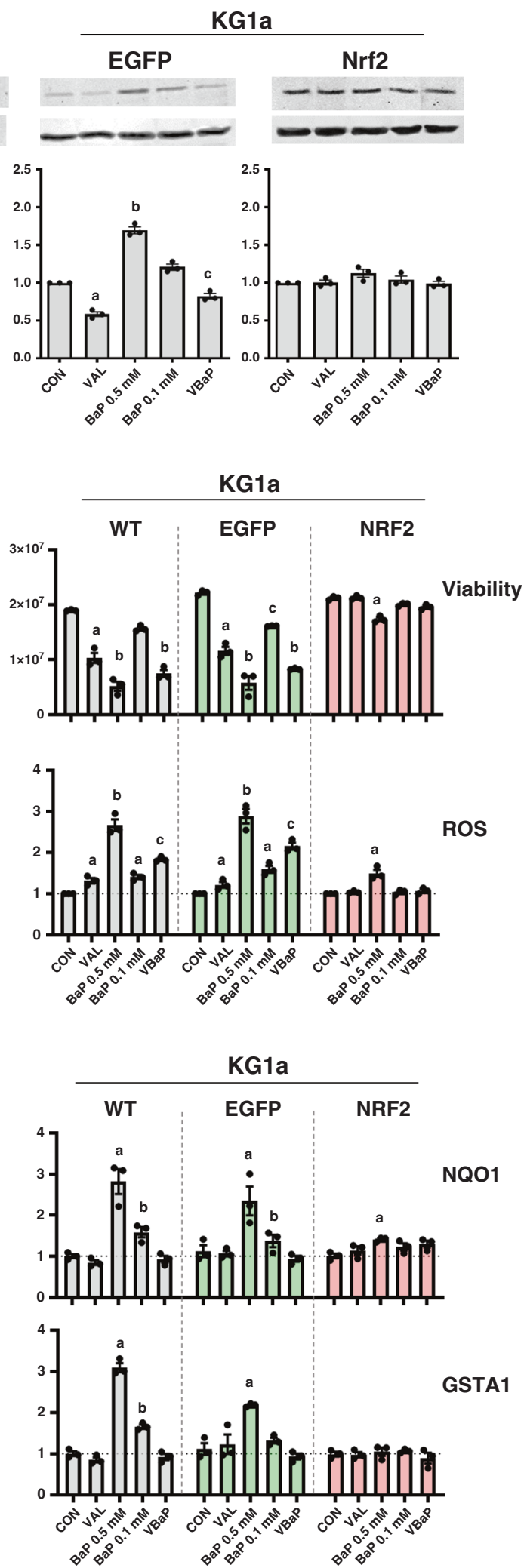

impact on quality of life and progression free survival in MDS patients. To test this, we have obtained funding and ethical approval for Repair-MDS, a phase 2 clinical trial comparing VBaP versus danazol [45] in MDS patients. This study will assess the impact of $\mathrm{VBaP}$ versus danazol on transfusion dependence, quality of life and transformation to AML. 
Fig. 6 Nrf-2 overexpression reverses the ability of VAL to potentiate the effects of low dose BaP. a WT, control-EGFP and -NRF2 transfected K562 and KG1a cells were treated as shown for $4 \mathrm{~h}$ and protein levels of Nrf2 determined using western blotting using $\beta$-actin as a loading control. Panels show representative images of blots. Bar charts show total Nrf2 protein levels relative to control as mean \pm SEM from $n=3$ experiments. b WT, control-EGFP and -NRF2 transfected K562 and KG1a cells were treated as shown for 7 days, with feeding and retreating every 2 days, and numbers of live cells determined by flow cytometry using counting beads. Bar charts shows mean \pm SEM for $n=3$ experiments. c WT, control-EGFP and -NRF2 transfected K562 and KG1a cells were treated for $24 \mathrm{~h}$, stained with carboxy- $\mathrm{H}_{2} \mathrm{DCFDA}$ for the detection of ROS and analysed by flow cytometry. Bar charts show mean data \pm SEM from $n=3$ experiments. d WT, control-EGFP and -NRF2 transfected K562 and KG1a cells were treated as shown for $4 \mathrm{~h}$ before extracting total RNA and synthesising CDNA. qRT-PCR was performed using gene-specific primers to Nrf2 target genes $\mathrm{NAD}(\mathrm{P}) \mathrm{H}$ dehydrogenase-quinone 1 (NQO1) and glutathione S-transferase A1 (GSTA1) expression. Data were normalised to $18 \mathrm{~s}$ rRNA and calculated as relative mRNA levels compared to solvent controls. Bar graphs show mean \pm SEM from $n=3$ experiments. Different letters indicate significant difference from other treatment groups $(p<0.05)$. Abbreviations: vehicle control (CON), $0.6 \mathrm{mM}$ Valproic acid (VAL), $0.5 \mathrm{mM} \mathrm{BEZ}$ and $5 \mu \mathrm{M}$ MPA (BaP $0.5 \mathrm{mM}$ ), $0.1 \mathrm{mM}$ BEZ and $5 \mu \mathrm{M}$ MPA (BaP 0.1 mM), the combination of Valproic acid $0.6 \mathrm{mM}$ and BaP $0.1 \mathrm{mM}$ (VBaP).

Importantly, there is increasing evidence that the NRF2 pathway is a driver of progression, metastasis, and resistance to therapy in many cancers [46]. Therefore, our findings demonstrating suppression of NRF2 activity by VAL highlight the potential of VAL as potential adjunctive therapy in other cancers.

\section{DATA AVAILABILITY}

All relevant data is available in the manuscript.

\section{REFERENCES}

1. Buechner T, Berdel WE, Haferlach C, Haferlach T, Schnittger S, Mueller-Tidow C, et al. Age-related risk profile and chemotherapy dose response in acute myeloid leukemia: a study by the German Acute Myeloid Leukemia Cooperative Group. J Clin Oncol. 2009;27:61-9.

2. Burnett AK, Hills RK, Milligan DW, Goldstone AH, Prentice AG, McMullin M-F, et al. Attempts to optimize induction and consolidation treatment in acute myeloid leukemia: results of the MRC AML12 Trial. J Clin Oncol. 2010;28:586-95.

3. Ashburn $\Pi$, Thor KB. Drug repositioning: Identifying and developing new uses for existing drugs. Nat Rev Drug Disco. 2004;3:673-83.

4. Wang ZY, Chen Z. Acute promyelocytic leukemia: from highly fatal to highly curable. Blood 2008;111:2505-15.

5. Palumbo A, Facon T, Sonneveld P, Blade J, Offidani M, Gay F, et al. Thalidomide for treatment of multiple myeloma: 10 years later. Blood 2008;111:3968-77.

6. Southam AD, Khanim FL, Hayden RE, Constantinou JK, Koczula KM, Michell RH, et al. Drug redeployment to kill leukemia and lymphoma cells by disrupting SCD1mediated synthesis of monounsaturated fatty acids. Cancer Res. 2015;75:2530-40.

7. Hayden RE, Kussaibati R, Cronin LM, Pratt G, Roberts C, Drayson MT, et al. Bezafibrate and medroxyprogesterone acetate target resting and CD40Lstimulated primary marginal zone lymphoma and show promise in indolent B-cell non-Hodgkin lymphomas. Leuk Lymphoma. 2015;56:1079-87.

8. Molyneux E, Merrick B, Khanim FL, Banda K, Dunn JA, lqbal G, et al. Bezafibrate and medroxyprogesterone acetate in resistant and relapsed endemic Burkitt lymphoma in Malawi; an open-label, single-arm, phase 2 study (ISRCTN34303497). Br J Haematol. 2014;164:888-90.

9. Hayden RE, Pratt G, Drayson MT, Bunce CM. Lycorine sensitizes CD40 ligand-protected chronic lymphocytic leukemia cells to bezafibrate- and medroxyprogesterone acetate-induced apoptosis but dasatanib does not overcome reported CD40-mediated drug resistance. Haematologica. 2010; 95:1889-96.

10. Murray JA, Khanim FL, Hayden RE, Craddock CF, Holyoake TL, Jackson N, et al. Combined bezafibrate and medroxyprogesterone acetate have efficacy without haematological toxicity in elderly and relapsed acute myeloid leukaemia (AML). Br J Haematol. 2010;149:65-9.

11. Khanim FL, Hayden RE, Birtwistle J, Lodi A, Tiziani S, Davies NJ, et al. Combined bezafibrate and medroxyprogesterone acetate: potential novel therapy for acute myeloid leukaemia. PLoS ONE. 2009;4:e8147.

12. Murray J, Pratt G, Jacob A, Clark F, Blundred R, Fox S, et al. Single arm phase II trial assessing the safety, compliance with and activity of Bezafibrate and medroxyProgesterone acetate (BaP) therapy against myeloid and lymphoid cancers. Contemp Clin Trials Commun. 2019;14:100361.

13. Zhou F, Shen Q, Claret FX. Novel roles of reactive oxygen species in the pathogenesis of acute myeloid leukemia. J Leukoc Biol. 2013;94:423-9.

14. Sillar JR, Germon ZP, Deluliis GN, Dun MD. The role of reactive oxygen species in acute myeloid leukaemia. Int J Mol Sci. 2019;20:6003.

15. AM AL, Syed DN, Ntambi JM. Insights into stearoyl-CoA desaturase-1 regulation of systemic metabolism. Trends Endocrinol Metab. 2017;28:831-42.
16. Abu Aboud O, Habib SL, Trott J, Stewart B, Liang S, Chaudhari AJ, et al. Glutamine addiction in kidney cancer suppresses oxidative stress and can be exploited for real-time imaging. Cancer Res. 2017;77:6746-58.

17. Gao L, Zackert WE, Hasford JJ, Danekis ME, Milne GL, Remmert C, et al. Formation of prostaglandins E2 and D2 via the isoprostane pathway: a mechanism for the generation of bioactive prostaglandins independent of cyclooxygenase. J Biol Chem. 2003;278:28479-89.

18. Birtwistle J, Hayden RE, Khanim FL, Green RM, Pearce C, Davies NJ, et al. The aldoketo reductase AKR1C3 contributes to 7,12-dimethylbenz(a)anthracene-3,4dihydrodiol mediated oxidative DNA damage in myeloid cells: implications for leukemogenesis. Mutat Res. 2009;662:67-74.

19. Penning TM, Sharp RB, Krieger NR. Purification and properties of 3 alphahydroxysteroid dehydrogenase from rat brain cytosol. Inhibition by nonsteroidal anti-inflammatory drugs and progestins. J Biol Chem. 1985;260:15266-72.

20. Hayden RE, Pratt G, Davies NJ, Khanim FL, Birtwistle J, Delgado J, et al. Treatment of primary CLL cells with bezafibrate and medroxyprogesterone acetate induces apoptosis and represses the pro-proliferative signal of CD40-ligand, in part through increased 15dDelta12,14,PGJ2. Leukemia 2009;23:292-304.

21. Scher JU, Pillinger MH. 15d-PGJ2: the anti-inflammatory prostaglandin? Clin Immunol. 2005;114:100-9.

22. Shibata T, Kondo M, Osawa T, Shibata N, Kobayashi M, Uchida K. 15-deoxy-delta 12,14-prostaglandin J2. a prostaglandin D2 metabolite generated during inflammatory processes. J Biol Chem. 2002;277:10459-66.

23. Kusano $Y$, Horie $S$, Shibata $T$, Satsu $H$, Shimizu M, Hitomi E, et al. Keap1 regulates the constitutive expression of GST A1 during differentiation of Caco- 2 cells. Biochemistry 2008;47:6169-77.

24. Gronningsaeter IS, Fredly HK, Gjertsen BT, Hatfield KJ, Bruserud O. Systemic metabolomic profiling of acute myeloid leukemia patients before and during disease-stabilizing treatment based on all-trans retinoic acid, valproic acid, and low-dose chemotherapy. Cells. 2019;8:1229.

25. Yuyama M, Fujimori K. Suppression of adipogenesis by valproic acid through repression of USF1-activated fatty acid synthesis in adipocytes. Biochem J. 2014;459:489-503.

26. Hole PS, Zabkiewicz J, Munje C, Newton Z, Pearn L, White P, et al. Overproduction of NOX-derived ROS in AML promotes proliferation and is associated with defective oxidative stress signaling. Blood 2013;122:3322-30.

27. Rushworth SA, Zaitseva L, Murray MY, Shah NM, Bowles KM, MacEwan DJ. The high Nrf2 expression in human acute myeloid leukemia is driven by NF-kappaB and underlies its chemo-resistance. Blood 2012;120:5188-98.

28. Ivars D, Orero MT, Javier K, Diaz-Vico L, Garcia-Gimenez JL, Mena S, et al. Oxidative imbalance in low/intermediate-1-risk myelodysplastic syndrome patients: the influence of iron overload. Clin Biochem. 2017;50:911-7.

29. Huang L, Liu Z, Jiang H, Li L, Fu R. Decitabine shows synergistic effects with arsenic trioxide against myelodysplastic syndrome cells via endoplasmic reticulum stress-related apoptosis. J Investig Med. 2019;67:1067-75.

30. Heasman SA, Zaitseva L, Bowles KM, Rushworth SA, Macewan DJ. Protection of acute myeloid leukaemia cells from apoptosis induced by front-line chemotherapeutics is mediated by haem oxygenase-1. Oncotarget 2011;2:658-68.

31. Zimta AA, Cenariu D, Irimie A, Magdo L, Nabavi SM, Atanasov AG, et al. The role of Nrf2 activity in cancer development and progression. Cancers (Basel). 2019;11:1755.

32. Karathedath S, Rajamani BM, Musheer Aalam SM, Abraham A, Varatharajan S, Krishnamurthy $P$, et al. Role of NF-E2 related factor 2 (Nrf2) on chemotherapy resistance in acute myeloid leukemia $(A M L)$ and the effect of pharmacological inhibition of Nrf2. PLoS ONE. 2017;12:e0177227.

33. Yu Jl, Choi C, Shin SW, Son A, Lee GH, Kim SY, et al. Valproic acid sensitizes hepatocellular carcinoma cells to proton therapy by suppressing NRF2 activation. Sci Rep. 2017;7:14986.

34. Pan $H$, Wang $H$, Jia $Y$, Wang $Q$, Li L, Wu $Q$, et al. VPA and MEL induce apoptosis by inhibiting the Nrf2-ARE signaling pathway in TMZ-resistant U251 cells. Mol Med Rep. 2017;16:908-14. 
35. Cha HY, Lee BS, Chang JW, Park JK, Han JH, Kim YS, et al. Downregulation of Nrf2 by the combination of TRAIL and Valproic acid induces apoptotic cell death of TRAIL-resistant papillary thyroid cancer cells via suppression of $\mathrm{BCl}-\mathrm{xL}$. Cancer Lett. 2016;372:65-74.

36. Russell N, Burnett A, Hills R, Betteridge S, Dennis M, Jovanovic J, et al. Attenuated arsenic trioxide plus ATRA therapy for newly diagnosed and relapsed APL: longterm follow-up of the AML17 trial. Blood. 2018;132:1452-4.

37. Li X, Dong Y, Li Y, Ren R, Wu W, Zhu H, et al. Low-dose decitabine priming with intermediate-dose cytarabine followed by umbilical cord blood infusion as consolidation therapy for elderly patients with acute myeloid leukemia: a phase II single-arm study. BMC Cancer. 2019;19:819.

38. Tremblay G, Westley T, Cappelleri JC, Arondekar B, Chan G, Bell TJ, et al. Overall survival of glasdegib in combination with low-dose cytarabine, azacitidine, and decitabine among adult patients with previously untreated AML: comparative effectiveness using simulated treatment comparisons. Clinicoecon. Outcomes Res. 2019;11:551-65.

39. Bug G, Ritter M, Wassmann B, Schoch C, Heinzel T, Schwarz K, et al. Clinical trial of valproic acid and all-trans retinoic acid in patients with poor-risk acute myeloid leukemia. Cancer. 2005;104:2717-25.

40. Tassara M, Dohner K, Brossart P, Held G, Gotze K, Horst HA, et al. Valproic acid in combination with all-trans retinoic acid and intensive therapy for acute myeloid leukemia in older patients. Blood. 2014;123:4027-36.

41. Stapnes C, Ryningen A, Hatfield K, Oyan AM, Eide GE, Corbascio M, et al. Functional characteristics and gene expression profiles of primary acute myeloid leukaemia cells identify patient subgroups that differ in susceptibility to histone deacetylase inhibitors. Int J Oncol. 2007:31:1529-38.

42. Khanim FL, Bradbury CA, Arrazi J, Hayden RE, Rye A, Basu S, et al. Elevated FOSBexpression; a potential marker of valproate sensitivity in $\mathrm{AML}$. $\mathrm{Br} J$ Haematol. 2009;144:332-41.

43. Birnbaum AK, Hardie NA, Conway JM, Bowers SE, Lackner TE, Graves NM, et al. Valproic acid doses, concentrations, and clearances in elderly nursing home residents. Epilepsy Res. 2004;62:157-62.

44. Felix S, Sproule BA, Hardy BG, Naranjo CA. Dose-related pharmacokinetics and pharmacodynamics of valproate in the elderly. J Clin Psychopharmacol. 2003;23:471-8.

45. Colunga-Pedraza PR, Colunga-Pedraza JE, Garza-Ledezma MA, Jaime-Perez JC, Cantu-Rodriguez OG, Gutierrez-Aguirre $\mathrm{CH}$, et al. Danazol as first-line therapy for myelodysplastic syndrome. Clin Lymphoma Myeloma Leuk. 2018;18:e109-e13.

46. Rojo de la Vega M, Chapman E, Zhang DD. NRF2 and the hallmarks of cancer. Cancer Cell. 2018;34:21-43.

\section{ACKNOWLEDGEMENTS}

None.

\section{AUTHOR CONTRIBUTIONS}

$\mathrm{CMB}$ and FLK jointly supervised this study.

\section{FUNDING}

This study was funded by a Programme Grant (13028) from Blood Cancer UK awarded to FLK, MTD and CMB.

\section{ETHICS APPROVAL AND CONSENT TO PARTICIPATE}

Primary blood samples from AML patients and normal donors were obtained as surplus to diagnosis samples and from normal donors (REC numbers 12/NW/0742 and ERN_17-0065). Healthy donor blood was obtained after informed consent under University of Birmingham (UoB) local ethical approval ERN_17-0065.

\section{CONSENT TO PUBLISH}

Not applicable.

\section{COMPETING INTERESTS}

The authors declare no competing interests.

\section{ADDITIONAL INFORMATION}

Supplementary information The online version contains supplementary material available at https://doi.org/10.1038/s41416-021-01570-z.

Correspondence and requests for materials should be addressed to Farhat $\mathrm{L}$. Khanim.

Reprints and permission information is available at http://www.nature.com/ reprints

Publisher's note Springer Nature remains neutral with regard to jurisdictional claims in published maps and institutional affiliations.

Open Access This article is licensed under a Creative Commons Attribution 4.0 International License, which permits use, sharing, adaptation, distribution and reproduction in any medium or format, as long as you give appropriate credit to the original author(s) and the source, provide a link to the Creative Commons license, and indicate if changes were made. The images or other third party material in this article are included in the article's Creative Commons license, unless indicated otherwise in a credit line to the material. If material is not included in the article's Creative Commons license and your intended use is not permitted by statutory regulation or exceeds the permitted use, you will need to obtain permission directly from the copyright holder. To view a copy of this license, visit http://creativecommons. org/licenses/by/4.0/

(c) The Author(s) 2021 